\title{
Caracterização Morfofisiológica e Anatômica de Paspalum urvillei (Steudel)
}

\author{
Simone Meredith Scheffer-Basso', Gabriel Laner Rodrigues ${ }^{2}$, Marta Vanise Bordignon ${ }^{3}$
}

\begin{abstract}
RESUMO - Este trabalho foi conduzido com o objetivo de caracterizar a dinâmica de afilhamento e acúmulo de biomassa, a fenologia e os aspectos anatômicos de P. urvillei. O ensaio foi desenvolvido em Passo Fundo, Rio Grande do Sul, onde foram colhidas quinzenalmente seis plantas, em um delineamento completamente casualizado, entre 21/10/99 a 21/04/00. As épocas foram avaliadas por unidades de graus-dia (GD) de crescimento, por intermédio da soma das temperaturas médias diárias (temperatura basal $=0{ }^{\circ} \mathrm{C}$ ). As características anatômicas de folha e colmo foram observadas por cortes histológicos à mão livre. O material foi corado com fucsina-azul de Astra e montado em glicerina, entre lâmina e lamínula. Observou-se um máximo de 70 afilhos/planta, sendo $60 \%$ basilares; a área foliar atingiu até $7066 \mathrm{~cm}^{2} /$ planta, com 250 folhas verdes/planta. A altura do dossel vegetativo manteve-se em $50 \mathrm{~cm}$. O florescimento foi precoce e longo, sugerindo a necessidade de manejo para encurtar tal estádio, a fim de prolongar o período de produção de folhas. Os estudos anatômicos comprovaram presença de células da bainha ao redor dos feixes vasculares, típico de plantas C4.
\end{abstract}

Palavras-chave: gramínea nativa, capim-das-roças

\section{Morphophysiological and Anatomic Characterization of Paspalum urvillei (Steudel)}

ABSTRACT - This work had the purpose to characterize the tillering and biomass accumulation dynamic, phenology and anatomic aspects. The experiment was conducted in Passo Fundo, Rio Grande do Sul, in which six plants were harvested every 15 days, between 21/10/99 to 21/04/00, in a completely randomized design. The times were accounted using units of growing degree-days (DD), calculated as the sum of the daily mean temperatures (threshold temperature $=0^{\circ} \mathrm{C}$ ). Transverse hand sections were used to observe the anatomic characteristics of leaf and stem. The material was stained with basic fuchsin Astra blue. It was observed a peak of 70 tillers/ plant, being $60 \%$ basal; the leaf area reached $7066 \mathrm{~cm}^{2} /$ plant, with 250 green leaves/plant. The height of the vegetative canopy remained with $50 \mathrm{~cm}$. The flowering time was early and long pointing out to a management practice to shorten this time to maintain the plants on continual leaf production. The anatomic evaluations confirmed the presence of sheath cells (Kranz) around of the vascular bundles, as $\mathrm{C} 4$ plants.

Key Words: native grass, vasey grass

\section{Introdução}

Entre os principais gêneros de gramíneas presentes nos campos subtropicais do Brasil, destaca-se Paspalum, com inúmeras espécies perenes de crescimento estival. Além de ser o gênero que engloba o maior número de espécies nativas, é também aquele que reúne o maior número de espécies com bom valor forrageiro (Valls, 1990). Suas espécies ocorrem em praticamente todas as comunidades herbáceas, desde as planícies encharcadas do Pantanal até as regiões litorâneas do Nordeste e, em muitas dessas formações vegetais, são dominantes e responsáveis pela produção da maior parcela da forragem disponível (Valls, 1987). No Rio Grande do Sul, a predominância do gênero Paspalum foi comprovada por Prestes et al. (1976), mas apenas algumas de suas espécies estão bem descritas quanto ao seu desenvolvimento morfológico. Segundo Valls (1990), 51 espécies de Paspalum já estão citadas no Rio Grande do Sul, mas coletas mais recentes evidenciam a presença de outras espécies, o que tem conduzido a novas coletas e ao aumento da disponibilidade de acessos. Dentre os grupos de Paspalum, destaca-se o Dilatata, de grande importância para o subtrópico, onde convivem biótopos sexuais e apomíticos de $P$. dilatatum Poiret, além de híbridos naturais. $P$. urvillei é a espécie do grupo com maior área de ocorrência no Brasil, sendo encontrado freqüentemente em terrenos perturbados dos estados do sul até o norte do país (Valls \& Pozzobon, 1987). Rosengurt et al. (1970) o descrevem como perene, com florescimento desde novembro até abril, vegetando no verão. Vive em campos e locais pouco pastejados, mas é apetecível quando

\footnotetext{
${ }^{1}$ Eng.-Agr., Dra., Prof. Titular, Universidade de Passo Fundo, Bairro São José, Passo Fundo, 99001-970. E.mail: simone@upf.tche.br ${ }^{2}$ Biólogo, Professor Estadual do Distrito Federal.

${ }^{3}$ Bióloga, MSc., Professora Adjunta da Universidade de Passo Fundo.
} 
jovem. É cespitoso, ereto, com 1 a 2,50 m de altura, sendo boa forrageira, apesar da tendência de tornarse fibroso com o avanço da maturidade (Burkart, 1969). As observações de campo indicam que é muito bem aceito por bovinos e eqüinos, consorciando-se bem com leguminosas estoloníferas, como trevobranco (Trifolium repens L.) e adesmia (Adesmia latifolia (Spreng.) Vog.), aumentando sua freqüência quando há redução da carga animal. Dall'Agnol \& Gomes (1987), ao compararem espécies de Paspalum, como $P$. dilatatum, $P$. guenoarum, $P$. notatum, entre outras, verificaram maior acúmulo de matéria seca em $P$. urvillei, demonstrando boa tolerância à geada, o que é prioritário para a região sul do Brasil. Devido à importância dessa espécie para a atividade pecuária com base em pastagens naturais, este estudo foi conduzido com os objetivos de descrever os principais aspectos do desenvolvimento morfológico de $P$. urvillei e analisar a anatomia da folha e colmo, com a finalidade de auxiliar em futuros estudos com a espécie.

\section{Material e Métodos}

O trabalho constou de um estudo de análise do crescimento morfológico de $P$. urvillei ao longo de treze meses (épocas), em delineamento completamente casualizado, com seis repetições. Assim, em cada época foram sorteadas seis plantas, dentre 96 plantas estabelecidas, para que fossem cortadas e analisadas estruturalmente.

O ensaio foi desenvolvido em Passo Fundo, região fisiográfica do Planalto Médio do Rio Grande do $\mathrm{Sul}$, tendo as coordenadas geográficas de $28^{\circ} 15^{\prime} \mathrm{S}$ e $52^{\circ} 24^{\prime} \mathrm{W}$ e $687 \mathrm{~m}$ de altitude média; o clima pertence à Zona Climática Fundamental Temperada $\mathrm{C}$, apresentando clima fundamental úmido (f) e variedade subtropical (Cfa) (Moreno, 1961). O material vegetal foi coletado em maio de 1999, em área de campo. Foram obtidas mudas, a partir da separação de afilhos de duas touceiras, que, colocadas em copos plásticos $(500 \mathrm{~mL})$ contendo solo, permaneceram sob telado até o plantio, em setembro de 1999. O ensaio foi instalado em solo corrigido de pH 6,0 e 15 dias após o plantio foi realizada uma aplicação de $30 \mathrm{~kg} \mathrm{de} \mathrm{N} / \mathrm{ha}$. A área experimental foi de $24 \mathrm{~m}^{2}$, sendo estabelecidas 96 mudas, distantes $0,50 \mathrm{~m}$ entre si. Após o plantio, as mudas receberam um corte de emparelhamento de 10 $\mathrm{cm}$ acima da sua base. Para referência do tempo de crescimento, utilizou-se a soma térmica (Romo \&

R. Bras. Zootec., v.31, n.4, p.1674-1679, 2002
Eddleman, 1995), considerando-se $0^{\circ} \mathrm{C}$ como temperatura basal. As amostragens foram realizadas em $21 / 10,4 / 11,18 / 11,2 / 12,16 / 12,30 / 12,13 / 1,27 / 1,10 / 2$, $24 / 2,9 / 3,25 / 3$ e $6 / 4$, totalizando 13 colheitas, que corresponderam a $610,878,1156,1400,1683,2035$, 2347, 2666, 2969, 3264, 356, 3844 e 4098 GD, respectivamente. Imediatamente antes das colheitas, as plantas foram avaliadas quanto à estatura, ao número e à origem dos afilhos. No laboratório, foram avaliados área foliar, número e peso de afilhos vegetativos e reprodutivos, número de folhas ativas (completamente verdes expandidas e emergentes), peso de lâminas foliares, bainhas foliares e inflorescências. $O$ material vegetal foi seco em estufa, durante 72 horas, a $70^{\circ} \mathrm{C}$. Os dados de peso de massa seca total, número de afilhos, número de folhas e área foliar foram submetidos à análise de regressão, tendo como variável independente a soma térmica $\left(\mathrm{GD} \mathrm{tb}=0^{\circ} \mathrm{C}\right)$. Para a escolha dos modelos matemáticos foram considerados os resultados da análise de regressão, o coeficiente de determinação $\left(\mathrm{R}^{2}\right)$, além da criteriosa observação dos dados obtidos. Para os estudos anatômicos, foram colhidos folhas e colmos de plantas em estádio reprodutivo. Posteriormente, foram realizados cortes anatômicos à mão livre, no sentido transversal, sendo o material corado com fucsinaazul de astra e montado entre lâmina e lamínula com glicerina $50 \%$. Os cortes foram analisados e fotografados em fotomicroscópio Olympus BX-50, em aumentos de 100 e 200x.

\section{Resultados e Discussão}

\section{Desenvolvimento morfológico}

A análise da variância revelou efeito da soma térmica sobre o número de afilhos e de folhas, área foliar e massa seca total das plantas, cujo comportamento em função da soma térmica foi avaliado com auxílio dos resultados da análise de regressão (Tabela 1).

Durante a estação de crescimento, houve intenso afilhamento (Figura 1), comprovando o vigor da espécie (Skerman \& Riveros, 1992). A maioria dos afilhos foi basilar, o que é importante sob o aspecto de manejo, uma vez que pode promover maior preservação dos meristemas e maior tolerância ao pastejo. Durante a primavera, um elevado percentual de afilhos manteve-se em estádio vegetativo, com um dossel vegetativo de cerca de $50 \mathrm{~cm}$, durante toda a estação de crescimento. O florescimento iniciou cedo (989 GD), foi progressivo e perdurou durante toda a esta- 
Tabela 1 - Quadrado médio do número de folhas (NF) e de afilhos (NA), área foliar (AF) e massa seca (MS) de $P$. urvillei Table 1 - Mean square of leaves number (LN) and tillers number (TN), leaf area (LA) and dry matter (DM) of $P$. urvillei

\begin{tabular}{|c|c|c|c|c|c|}
\hline \multirow[t]{2}{*}{$\begin{array}{l}\text { Causas de variação } \\
\text { Source of variation }\end{array}$} & \multirow[t]{2}{*}{$\begin{array}{l}\text { GL } \\
D F\end{array}$} & \multicolumn{4}{|c|}{$\begin{array}{l}\text { Q.M. } \\
M . S\end{array}$} \\
\hline & & NF & NA & $\mathrm{AF}$ & MS \\
\hline $\begin{array}{l}\text { Regressão } 1^{\mathrm{o}} \text { grau } \\
\text { Regression } 1^{\text {st }} \text { degree }\end{array}$ & 1 & $104400,75^{* *}$ & $22066,70^{* *}$ & $107545020,92 * *$ & $29887,95 * *$ \\
\hline $\begin{array}{l}\text { Regressão } 2^{\circ} \text { grau } \\
\text { Regression } 2^{\text {nd }} \text { degree }\end{array}$ & 1 & $166354,03 * *$ & $13642,21 * *$ & $169207732,09 * *$ & $18492,25 * *$ \\
\hline $\begin{array}{l}\text { Regressão } 3^{\circ} \text { grau } \\
\text { Regression } 3^{\text {rd }} \text { degree }\end{array}$ & 1 & 1741,51 & 295,63 & $39900604,75 * *$ & $6365,47 * *$ \\
\hline
\end{tabular}

ção de crescimento (Figura 1). Esse comportamento também foi relatado por Skerman \& Riveros (1992), o que é indesejável, tanto sob aspecto de nutrição animal, como para a colheita de sementes. Há, assim, necessidade de manejo que permita maior sincronização do florescimento. Os afilhos reprodutivos alcançaram estatura elevada, alguns com mais de dois metros de comprimento. Segundo critérios de Almeida (1995), pode-se classificar $P$. urvillei como uma espécie de ciclo longo (PCL), o que, segundo a autora, é comum em espécies eretas.

Concomitantemente ao afilhamento, houve ativa produção de folhas. Os pontos de máxima densidade de folhas verdes e área foliar ocorreram aos 2666 e 2969 GD, respectivamente (Figura 2), revelando uma relação positiva com o afilhamento.

$\mathrm{Na}$ composição das folhas, observou-se aumento da proporção de bainha, em relação à lâmina, de $20 \%$ até cerca de $50 \%$ da massa seca foliar (Figura 2). Segundo Nabinger (1996), o comprimento da bainha é uma importante característica estrutural da pastagem, que deve ser levada em conta no manejo, pois restringe o consumo, afeta a taxa de aparecimento e a senescência foliar, assim como a plasticidade das gramíneas em resposta à intensidade de desfolhação. O comprimento final da bainha e lâmina aumenta em sucessivas folhas até obter um comprimento constante; esse padrão é revertido quando os entrenós alongam, havendo maior encurtamento das lâminas em relação às bainhas, de forma que as maiores folhas situam-se no centro do dossel e a folha mais curta é a folha bandeira, que possui longa bainha (Skinner \& Nelson, 1995). Isso foi confirmado neste trabalho, em que, com o progressivo alongamento dos entrenós, na época do florescimento, a bainha ocupou uma faixa cada vez

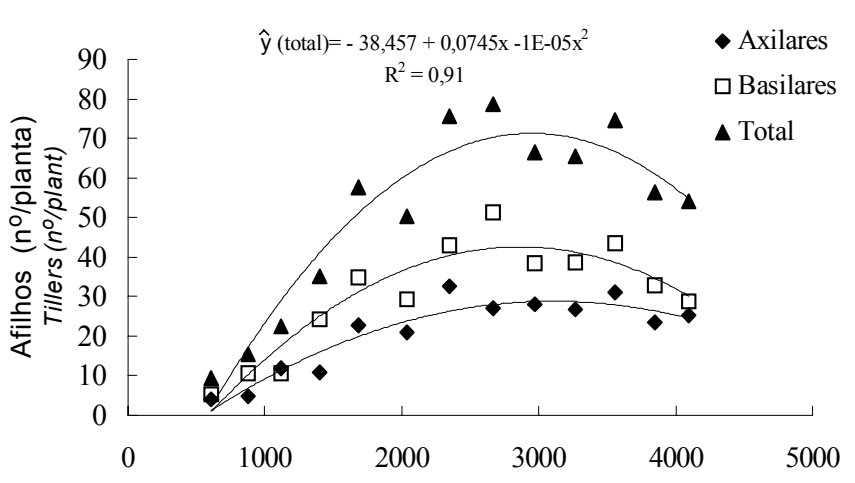

$\mathrm{GD}$ tb $=0^{\circ} \mathrm{C}$

DD

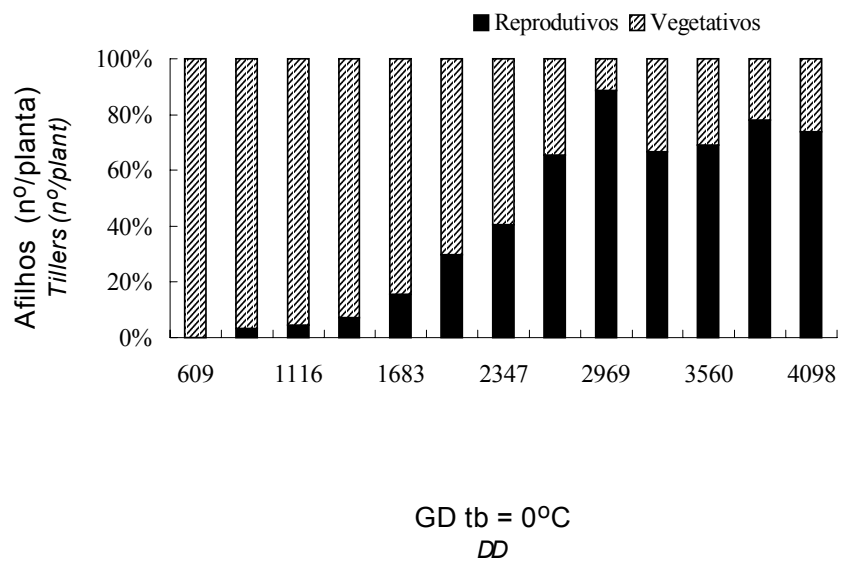

Figura 1 - Dinâmica de afilhos totais, basilares e axilares e distribuição de afilhos vegetativos e reprodutivos de plantas individuais de $P$. urvillei em função de graus-dia (GD, temperatura basal $=0^{\circ} \mathrm{C}$ ).

Figure 1 - Dynamic of total tillers, basal and axillaries tillers and distribution of vegetative and reproductive tillers of the individual plants of $P$. urvillei as a function of the degree-day ( $D D$, threshold temperature $=0^{\circ} \mathrm{C}$ ). 

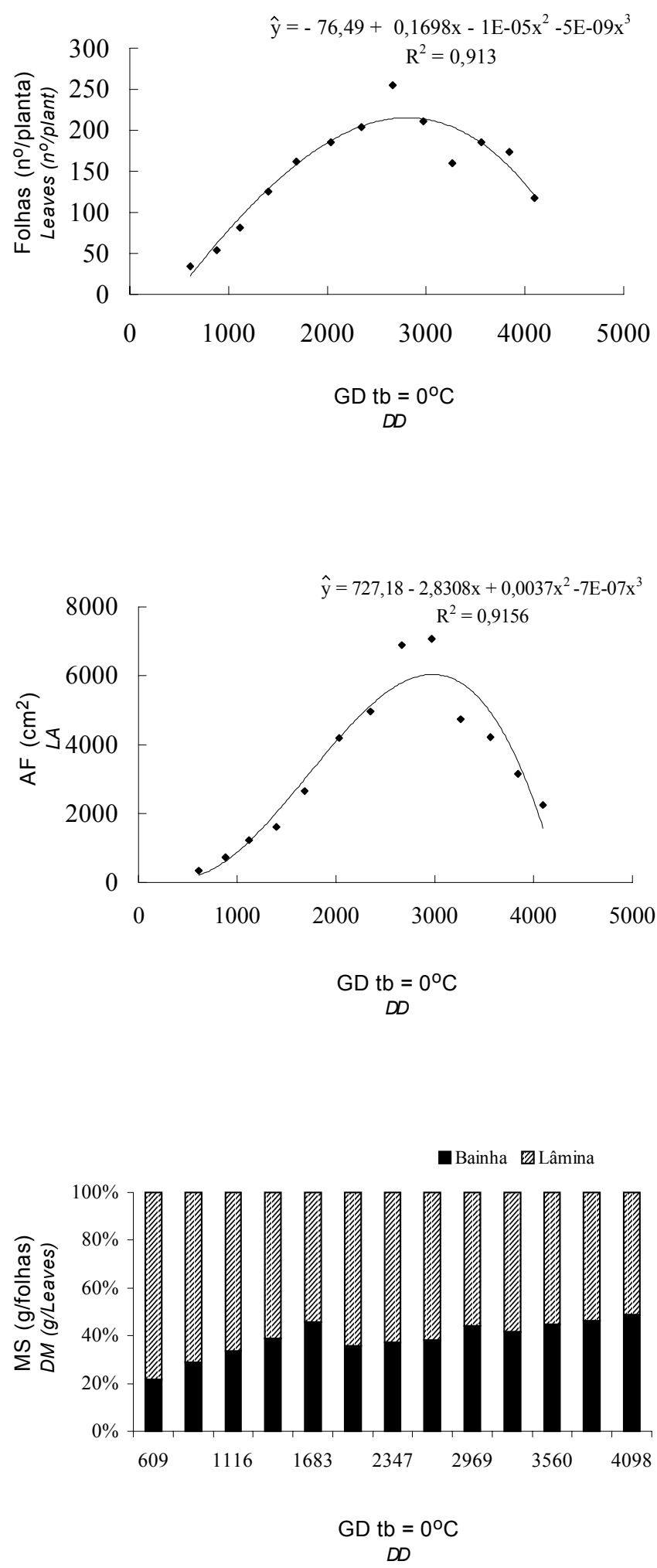

Figura 2 - Dinâmica da produção de folhas ativas, área foliar (AF) e composição das folhas (bainha e lâmina) de $P$. urvillei, em função de graus-dia (GD, temperatura basal de $0^{\circ} \mathrm{C}$ ).

Figure 2 - Dynamic of active leaves production, leaf area (AF) and leaves composition (sheath and blade) of $P$. urvillei as a function of the degree-days $(D D$, threshold temperature $=0^{\circ} \mathrm{C}$ ). mais extensa do colmo, em detrimento da porção laminar.

Quanto ao acúmulo de biomassa aérea, observou-se que, no início do crescimento, os aumentos foram pequenos, mas, com o acúmulo de GD, houve rápido incremento no peso das plantas, atingindo 335,75 g MS/planta, aos 2969 GD (Figura 3). Na análise da alocação da biomassa aérea, verificou-se decréscimo progressivo das folhas, estabilizando-se aos 2969 GD. Até $1400 \mathrm{GD}$, as folhas compreendiam $70 \%$ do total acumulado de MS. O percentual de inflorescência manteve-se praticamente estável ao longo do período. No geral, verificou-se que, para os parâmetros estudados, um acúmulo de 3000 GD $\left(t b=0^{\circ} \mathrm{C}\right)$ representou uma época de estabilização na

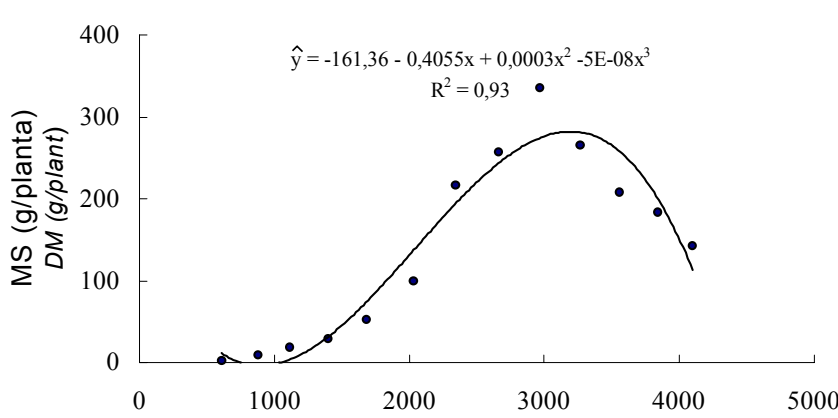

GD tb $=0^{\circ} \mathrm{C}$

$D D$

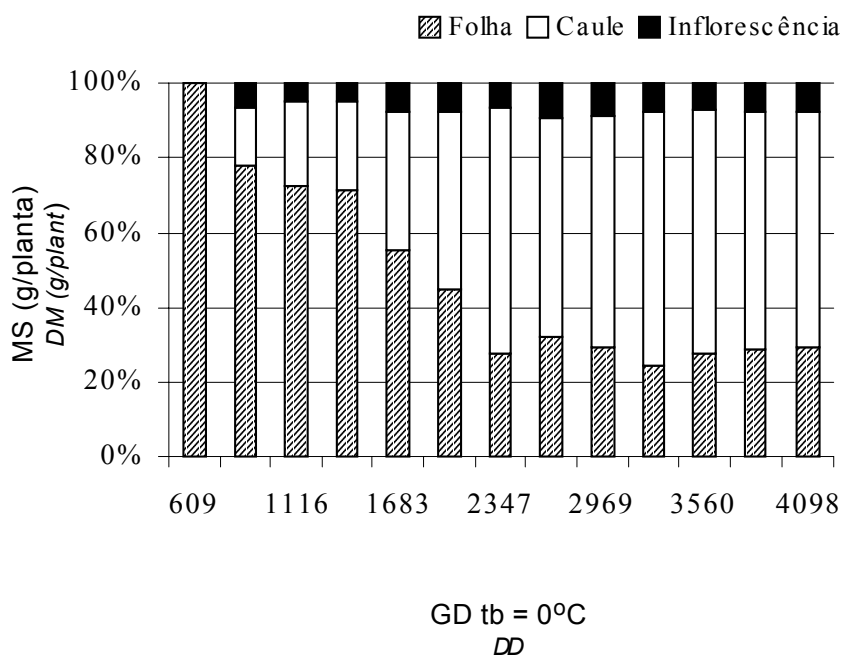

Figura 3 - Dinâmica do acúmulo de matéria seca e participação relativa de folhas, caules e inflorescências de $P$. urvillei, em função de graus-dia (GD, temperatura basal de $0^{\circ} \mathrm{C}$ ).

Figure 3 - Dynamic of dry matter accumulation as a function of the degree-day $\left(D D\right.$, threshold temperature $\left.=0^{\circ} \mathrm{C}\right)$. 
repartição da massa seca. A partir daí, as plantas entraram numa fase de intensa senescência, que determinou a perda de área foliar, afilhos e biomassa aérea, culminando com o final do seu ciclo produtivo. Portanto, a utilização dessa gramínea deveria ser antecipada para o período no qual a formação de folhas é intensa.

\section{Características anatômicas}

Os cortes histológicos comprovaram a anatomia C4 para P. urvillei, tal como se observou para as outras espécies do gênero, como em $P$. notatum (Santos et al., 1999) e P. repens Berg. (Kita et al., 1999). As células do mesofilo se dispõem radialmente em torno dos feixes apresentando muitos cloroplastos (Figura 4A).

A lâmina foliar possui epiderme uniestratificada com células de parede sinuosa, característica de gramíneas tropicais, o que as tornam mais resistentes à fragmentação (Minson \& Wilson, 1994). Segundo esses autores, o tipo de perfil apresentado pela epiderme das folhas influencia o seu grau de resistência à ruptura; em leguminosas, são lobadas; em gramíneas temperadas de ciclo $\mathrm{C} 3$, retas; e em gramíneas tropicais, sinuosas. Na superfície adaxial da lâmina foliar, aparecem células buliformes (Figura 4A), que são volumosas, de contorno quadrangular, semelhantes àquelas encontradas por Aliscioni \& Arriaga (1998) para Paspalum spp. Tais células são responsáveis pelo enrolamento da folha de $P$. urvillei, aspectos visíveis a olho nu. Os estômatos são encontrados em ambas as faces, havendo a predominância dos mesmos na face abaxial.

Os feixes vasculares são de tamanhos diferentes, sendo que os maiores se ligam por pequenos feixes anastomosantes. Observou-se a existência de somente duas a quatro células entre as bainhas dos feixes, lateralmente, similar ao que se encontra em P. dilatatum (Burkart, 1969). A quilha é formada por parênquima fundamental, sendo que próximo à superfície abaxial se concentram células com cloroplastos (Figura 4B). A bainha da folha apresenta epiderme uniestratificada com cutícula mediamente espessa. $\mathrm{Na}$ face abaxial da bainha foliar (Figura 4C), encontram-se feixes de fibras, que se localizam logo abaixo da superfície, conforme observado por Burkart (1969), para $P$. notatum. A mesma figura mostra o feixe vascular com cavidades de ar nas laterais, as quais também caracterizam a anatomia da bainha foliar de $P$. densum Poir. e P. millegrama Schrad., conforme observação de Aliscioni \& Arriaga (1998). Nos colmos,

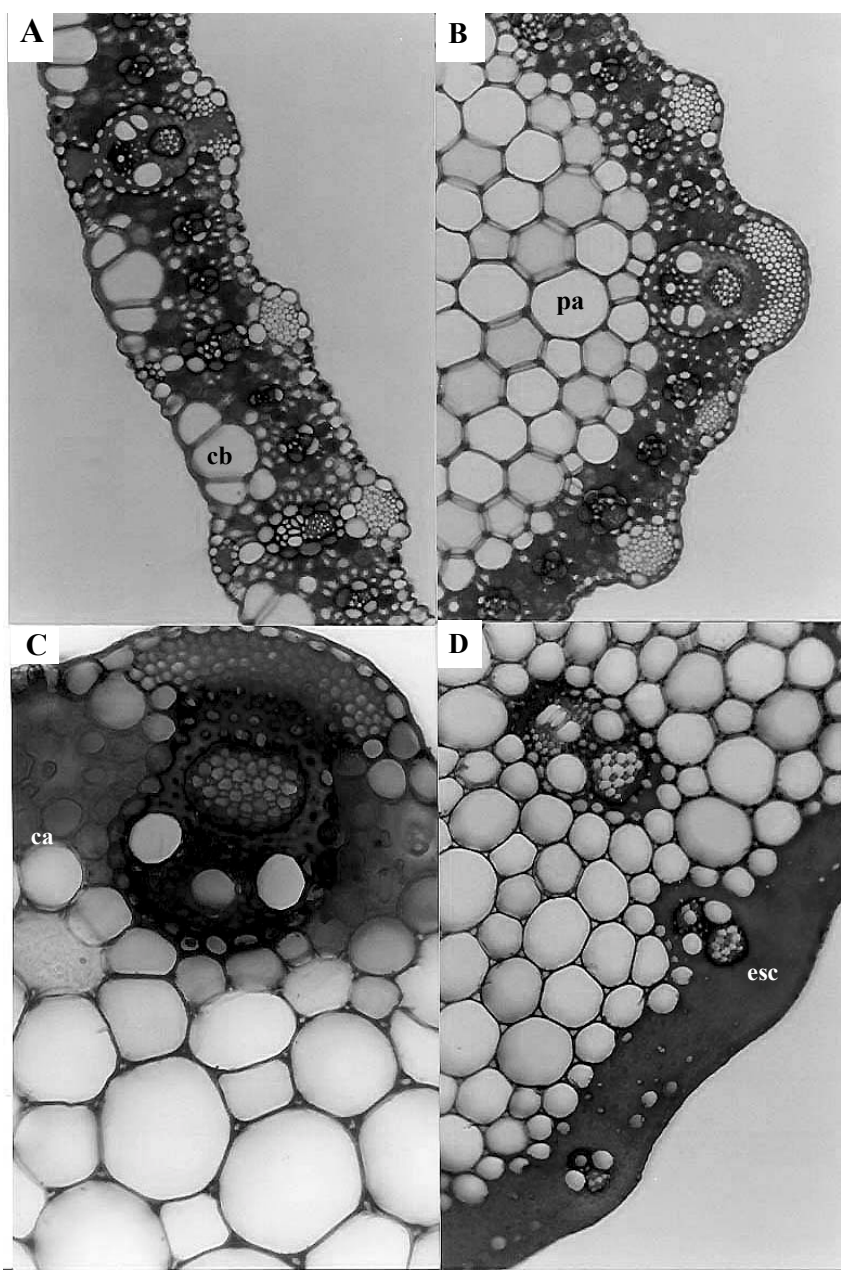

Figura 4 - Detalhes da anatomia da folha de $P$. urvillei; (A) lâmina foliar - 100x (cb) células buliformes, (B) quilha - 100x (pa) parênquima, (C) bainha foliar - 200x (ca) cavidade de ar, (D) colmo $100 x$ (esc) bainha de esclerênquima.

Figure 4 - Details of leaf anatomy of $P$. urvillei; $(A)$ leaf blade - 100x (cb) bulliforms cells; (B) keel - 100x (pa) parenchyma; (C) leaf sheath - 200x (ca) air cavity; (D) culm - 100x (esc) sclerenchyma sheath.

a epiderme é uniestratificada, com faixa densa de esclerênquima e feixes vasculares distribuídos em seu interior (Figura 4D). Ocorre também parênquima fundamental. Em análises de colmos de partes mais velhas do vegetal, observou-se que paredes celulares de células parenquimáticas próximas à faixa periférica de esclerênquima não se coraram com azul de astra (paredes celulósicas), e sim com fucsina, indicando a presença de lignina nas paredes. Resultado similar foi registrado por Brito et al. (1999) em capim-elefante, cujo envelhecimento promoveu o espessamento e lignificação de paredes celulares, especialmente na

\section{R. Bras. Zootec., v.31, n.4, p.1674-1679, 2002}


região próxima aos feixes. Salienta-se que a deposição de lignina reduz sensivelmente a digestibilidade das forragens, afetando negativamente o consumo voluntário dos animais e, conseqüentemente, a produção animal.

As características anatômicas da espécie mostram, portanto, o elevado grau de lignificação nos estádios fenológicos mais avançados. Isso reforça a importância de práticas de manejo que retardem e concentrem o florescimento, de modo que os animais tenham a sua disposição uma forragem mais folhosa e, portanto, mais nutritiva.

\section{Conclusões}

P. urvillei é uma gramínea tipicamente cespitosa, com elevado número de afilhos e ciclo produtivo marcantemente estival. Com o envelhecimento, há um aumento progressivo na participação de colmos, bainhas foliares e panículas na biomassa aérea das plantas. Fenologicamente, é uma espécie precoce de ciclo longo e o extenso período de florescimento representa uma limitação a ser superada, para permitir seu melhor aproveitamento como planta forrageira. Anatomicamente, é uma espécie $\mathrm{C} 4$, com elevado grau de lignificação em estádios avançados de florescimento, o que reforça a importância do manejo, de modo a manter a planta em estádio vegetativo o maior tempo possível.

\section{Literatura Citada}

ALISCIONI, S.; ARRIAGA, M. Estúdio histofoliar de las especies de los grupos Virgata y Quadrifaria del género Paspalum L. (Poaceae-Panicoideae - Paniceae). Candolle, v.53, n.2, p.333-348, 1998.

ALMEIDA, S.P. Grupos fenológicos da comunidade de gramíneas perenes de um campo cerrado no Distrito Federal do Brasil. Pesquisa Agropecuária Brasileira, v.30, n.8, p.1067-1073, 1995.

BRITO, C.I.F.A.; RODELLA, R.A.; DESCHAMPS, F.C. et al. Anatomia quantitativa in vitro de tecidos em cultivares de capim-elefante (Pennisetum purpureum Schumach). Revista Brasileira de Zootecnia, v.28, n.2, p.223-229, 1999.

BURKART, A. Flora ilustrada Entre Rios (Argentina). Parte II - Gramíneas. Buenos Aires: Collección Científica del INTA, 1969. 551p.

DALL'AGNOL, M.; GOMES, K.E. Avaliação inicial da produção de matéria seca de espécies de gênero Paspalum. In: ENCONTRO INTERNACIONAL SOBRE MELHORAMENTO GENÉTICO DE PASPALUM, 1987, Nova Odessa. Anais... Nova Odessa: 1987. p.51-55.
KITA, K.K.; PIRES, M.M.Y.; SOUZA, L.A. Morfoanatomia de Paspalum repens Berg. (Poaceae) da planície e inundação do Alto Rio Paraná. In: CONGRESSO DE BOTÂNICA, 50., 1999, Blumenau. Anais... Blumenau: Sociedade Brasileira de Botânica, 1999. p.21.

MINSON, D.J.; WILSON, J.R. Prediction of intake as an element os forage quality. In: FAHEY, G.C. (Ed.) Forage quality, evaluation and utilization. Madison: ASA, 1994. p.533-563.

MORENO, J.A. Clima do Rio Grande do Sul. Porto Alegre: Secretaria da Agricultura. 1961. 41p.

NABINGER, C. Aspectos ecofisiológicos do manejo de pastagens e utilização de modelos como ferramenta de diagnóstico e indicação de necessidades de pesquisa. In: REUNIÃO DO GRUPO TÉCNICO REGIONAL DO CONE SUL (ZONA CAMPOS) EM MELHORAMENTOS E UTILIZAÇÃO DE RECURSOS FORRAGEIROS DAS ÁREAS TROPICAL E SUBTROPICAL, 1996, Porto Alegre. Anais... Porto Alegre: Universidade Federal do Rio Grande do Sul, 1996. p.17-62.

PRESTES, P.J.Q.; FREITAS, E.A.G.; BARRETO, I.L.B. Hábito vegetativo e variação estacional do valor nutritivo das principais gramíneas da pastagem nativa do Rio Grande do Sul. Anuário Técnico IPZFO, v.3, 516-531, 1976.

ROMO, J.T.; EDDLEMAN, L.E. Use of degree-days in temperature experimentas. Journal of Range Management, v. 48, n. 5 , p. $410-416,1995$.

ROSENGURT, B.; MAFFEI, B.A.; ARTUCIO, P.I. Gramíneas uruguayas. Montevideo: Universidad Publicaciones, 1970.489p.

SANTOS, M.; MIGUENS, F.C.; OLIVERIA, P.L. Aspectos da anatomia foliar de Paspalum notatum Flugge crescendo em área com rejeitos de mineração de carvão e fora desta. In: CONGRESSO DE BOTÂNICA, 50., 1999, Blumenau. Anais... Blumenau: 1999. p.44.

SKERMAN, P.J.; RIVEROS, F. Gramínea tropicales. Roma: FAO, 1992. 849p.

SKINNER, R.H.; NELSON, C.J. Elongation of the grass leaf and its relationship to the phyllochron. Crop Science, v.35, p.4-10, 1995.

VALLS, J.F.M. A busca de germoplasma de plantas forrageiras e estratégias para sua coleta. In: PUIGNAU, J.P. (Ed.). Introduccion, conservacion y evaluacion de germoplasma forragero en el cono sur. Montevideo: IICA - PROCISUR, 1990. p.309-318. (Dialogo 8)

VALLS, J.F.M. Recursos genéticos de espécies de Paspalum no Brasil. In: ENCONTRO INTERNACIONAL SOBRE MELHORAMENTO GENÉTICO DE PASPALUM, 1987, Nova Odessa. Anais... Nova Odessa: 1987. p.15-23.

VALLS, J.F.M.; POZZOBON, M.T. Variação apresentada pelos principais grupos taxonômicos de Paspalum com interesse forrageiro no Brasil. In: ENCONTRO INTERNACIONAL SOBRE MELHORAMENTO GENÉTICO DE PASPAlUM, 1987, Nova Odessa. Anais... Nova Odessa: 1987. p.15-21. 